\title{
EDUCAÇÃO COMO PRÁTICA DA LIBERDADE E A PERSPECTIVA DA EDUCAÇÃO INTEGRAL NO ENSINO SUPERIOR
}

\author{
EDUCATION AS PRACTICE OF FREEDOM AND THE \\ PERSPECTIVE OF INTEGRAL EDUCATION IN HIGHER \\ EDUCATION
}

\section{EDUCACIÓN COMO PRÁCTICA DE LIBERTAD Y LA PERSPECTIVA DE EDUCACIÓN INTEGRAL EN EDUCACIÓN SUPERIOR}

João Ricardo Silva ${ }^{\mathrm{I}}$

Tânia Suely Azevedo BrasileiroII

IUniversidade Federal do Oeste do Pará, Pará - Brasil. E-mail: joaoricardoatm@outlook.com

IIUniversidade Federal do Oeste do Pará, Pará - Brasil. E-mail: brasileirotania@gmail.com

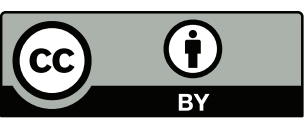

Educação: Teoria e Prática, Rio Claro, SP, Brasil - eISSN: 1981-8106

Está licenciada sob Licença Creative Common

\section{Resumo}

Neste artigo discutimos a ideia de educação como prática da liberdade, tendo em conta uma perspectiva emancipatória de educação integral para o ensino superior. Assim, refletimos sobre uma educação integral em contraposição à versão hegemônica e simplista de uma educação para o mercado e até mesmo em contraposição àquela que significa absorção de conhecimentos 
objetivos superiores. A metodologia utilizada foi a pesquisa bibliográfica, onde buscamos uma síntese dinâmica entre autores(as) marxistas e a discussão decolonial/pós-colonial. O horizonte teórico foi de um materialismo histórico dialético, mas sem descurar que os conhecimentos estão para além do olhar ocidental e que a ciência não é a única lógica de conhecimento válida. Tendo em vista que o conhecimento é não só reflexo da realidade, mas a interpretação desta, a busca por uma educação integral é também a busca por interconhecimento. Isso nos leva a dessacralizar a universidade e a transformá-la em local de construção de relações democráticas.

Palavras-chave: Educação Integral. Práticas da liberdade. Ensino Superior.

\section{Abstract}

In this article we discuss education as a freedom practice, considering an emancipatory perspective of Integral Education for Higher Education. Thus, we reflect on integral education in opposition to the hegemonic and simplistic version of education for the market and even in opposition to the education that aims to absorb superior objective knowledge. The methodology used was the bibliographical research, where we sought a dynamic synthesis between Marxist authors and the colonial / postcolonial discussion. The theoretical horizon was a dialectical historical materialism, but considering that knowledge is beyond the Western gaze and that science is not the only valid knowledge. Given that knowledge is not only a reflection of reality, but the interpretation of this, the search for an integral education is also the search for inter-knowledge. This leads us to desacralize the university and to transform it into a place of building democratic relations.

Keywords: Integral Education. Practices of Freedom. Higher Education.

\section{Resumen}

En este artículo discutimos la idea de Educación como Práctica de la Libertad, teniendo en cuenta una perspectiva emancipatoria de Educación Integral para la Enseñanza Superior. Así, reflexionamos sobre una educación integral en contraposición a la versión hegemónica y simplista de una educación para el mercado e incluso en contraposición a la que significa absorción de conocimientos objetivos superiores. Utilizamos la metodología de la investigación bibliográfica, donde buscamos una síntesis dinámica entre autores y autoras marxistas y la discusión decolonial/poscolonial. El horizonte teórico fue el materialismo histórico dialéctico, pero sin descuidar que los conocimientos están más allá de la mirada occidental y que la 
ciencia no es la única lógica de conocimiento válida. Teniendo en cuenta que el conocimiento no es sólo reflejo de la realidad, pero de su interpretación, la búsqueda de una educación integral es también la búsqueda de interconocimiento. Así, desacralizamos la universidad y la transformamos en un lugar de construcción de relaciones democráticas.

Palabras clave: Educación Integral. Prácticas de libertad. Educación superior.

\section{INTRODUÇÃO}

As discussões sobre educação integral já vêm de longa data, constituindo um ideal tanto presente na legislação brasileira como nas formulações de muitos educadores. Ao que se refere especificamente à ideia de educação integral no ensino superior, não foram encontradas muitas discussões a respeito, o que nos levou a questionar a importância e possibilidade deste tipo de educação para o referido nível reportado neste artigo.

Neste sentido, no primeiro subitem foi feita uma discussão sobre o que é educação integral e quais as necessidades e possibilidades desta para o ensino superior. Já no subitem 2 foi feito um debate crítico da educação para o mercado tendo como fundamento a ideia de que é necessário pensarmos para além do Capital. No subitem 3 trabalhamos a Ecologia de saberes, haja vista que estas são um conjunto de saberes plurais capazes de sustentar práticas também plurais dentro de uma interculturalidade de conhecimentos, o que nos permitiu pensar para além das práticas hegemônicas. Para abarcar a ideia de múltiplos saberes, o último subitem (4) desenvolveu uma discussão acerca da busca por uma universidade de ideias em contraposição à lógica de uma ideia de universidade.

Utilizamos a abordagem qualitativa, onde nos servimos da pesquisa bibliográfica. Já do ponto de vista dos objetivos a proposta metodológica foi exploratória e descritiva. O método teórico de investigação utilizado - enquanto trajetória teórica que expressa uma visão de mundo, ser humano e conhecimento - foi o Materialismo Histórico Dialético, mas reinterpretado por uma visão decolonial, ou seja, não tomamos a ciência como forma de chegarmos ao conhecimento absoluto. Neste sentido, a análise aqui feita tem por base que a crítica teórica pode partir do campo das ideias, mas deve vir acompanhada de sua relação com a realidade material, já que o modo de produção da vida material condiciona (não determina), em última instância, (e dialeticamente é condicionado pelo) o processo da vida social, política e espiritual em geral. 


\section{EDUCAÇÃO INTEGRAL VERSUS EDUCAÇÃO PARA O MERCADO CAPITALISTA}

É importante destacar que diferentes visões sociais de mundo (liberal, conservadora, socialista, anarquista, etc.) vão construir perspectivas de educação integral de formas diversas. Se pensarmos "historicamente, as reflexões sobre uma formação mais completa remontam ao início da civilização humana e, com ela, perpassam matrizes ideológicas bem diferentes em termos político-filosóficos" (COELHO, 2009, p. 85).

Como afirma Coelho (2009, p. 90), "podemos dizer que a educação integral se caracteriza pela busca de uma formação a mais completa possível para o ser humano", mas em todo caso os pressupostos teóricos e as abordagens metodológicas para a constituição de tal integralidade são de uma significativa diversidade, havendo uma pluralidade de concepções referentes ao que se entende por este tipo de educação.

Para Guará (2006, p. 16), a ideia de educação integral está ligada à ideia filosófica de ser humano integral, "realçando a necessidade de desenvolvimento integrado de suas faculdades cognitivas, afetivas, corporais e espirituais". A partir deste ponto de vista, para chegarmos a esse desenvolvimento integral se faz necessário espaços educativos que não estejam relacionados apenas à formação intelectual ou técnica, mas que possibilite às/aos atrizes/atores envolvidos as possibilidades de desenvolverem inteiramente a sua humanidade. Isso significa que também é um objetivo o desenvolvimento pleno do(a) educador(a), tratando-se de uma construção conjunta, recíproca e não unilateral.

Nessa perspectiva, a educação integral não pode estar restrita ao ensino básico, deve ir além. Afinal, para as classes oprimidas pelo Sistema Sociometabólico do Capital ${ }^{1}$ é notável que a perspectiva das lutas é pautada pela melhoria de condições de vida não só durante a escola, já que a exploração não se dá apenas numa fase da vida, mas permeia toda a sociedade e atinge todas as idades.

Como as opressões permeiam toda a sociedade em maior ou menor grau, é necessário o aumento de práticas democráticas em todos os espaços estruturais. Afinal, são nesses múltiplos espaços que se formam as subjetividades. ${ }^{2}$ Neste sentido, uma educação integral tem a ver com

\footnotetext{
${ }^{1}$ Este termo vem de Mészáros (2007) e, segundo Foster (2007, p. 14), quer significar que o sistema do capital permeia todos os aspectos da sociedade, sendo uma ordem particular de "controle sociometabólico".

${ }^{2}$ A demarcação dos Espaços Estruturais é feita segundo a teoria de Santos (2010, 2011b) e conforme Aranha (2011, p. 90): “Os espaços estruturais das sociedades capitalistas são identificados por Santos a partir de seis conjuntos principais de relações sociais. Dentro de cada um dos seis espaços estruturais se produz, respectivamente, uma forma específica de poder, de direito e de conhecimento de senso comum que, embora estruturalmente autônomos, são inter-relacionados $[\ldots]$ ”.
} 
a educação como prática da liberdade, pois é pensada de forma emancipatória e se desenvolve enquanto "democratização da democracia"3, ampliando os espaços democráticos para além da democracia representativa e para além dos espaços formais de educação.

Isso implica "pensar na possibilidade de desenvolvimento da autonomia intelectual e social dos sujeitos individuais e coletivos envolvidos no processo educativo" (OLIVEIRA, 2008, p. 101). Ou seja, os meios e as finalidades de práticas emancipatórias se dão pela possibilidade de desenvolver relações sociais mais justas e igualitárias, não somente nas escolas ou nas universidades, como também em toda sociedade.

Essa educação não fica condicionada aos anos iniciais de escolarização e tampouco aos espaços formais. A educação formal e a informal devem caminhar juntas para gerar o pleno desenvolvimento humano, "contribuindo para a construção da cidadania, conhecimento dos direitos fundamentais, respeito à pluralidade e à diversidade sexual, étnica, racial, cultural, de gênero e de crenças religiosas" (MOLL, 2011, p. 44).

A educação é um processo amplo, complexo, dinâmico e permanente. Ela é a própria vida, no sentido que não está restrita aos espaços educacionais formais. Tem de ir além dos currículos tradicionais, envolver as várias dimensões da realidade pelas quais transita e “considerar os saberes, as histórias, as trajetórias, as memórias, as sensibilidades dos grupos e dos sujeitos com os quais trabalha" (MOLL, 2008, p. 15).

A tarefa é ampliar a humanização não apenas no sentido cognitivo, mas possibilitar a formação de subjetividades inconformistas e rebeldes que estejam dispostas a discutir os conflitos sociais - não apenas escondê-los como se não existissem - e lutar contra o sofrimento humano injusto que ainda permeia a sociedade. Para Freire (2014) essa educação é aquela que, desvestida da roupagem alienada e alienante, se torna uma força de mudança e de libertação.

Além do mais, a educação não é simples processo de transmissão de saber ou transmissão de conhecimentos neutros. Os saberes são necessariamente conhecimentos do mundo e da realidade, por isso são limitados pelas condições de existência e pelos contextos em que são produzidos. Como observa Guará (2006), os currículos formais devem se aproximar do contexto existencial para que as prioridades das práticas educativas estejam vinculadas àqueles temas que hoje são colocados em segundo plano e acabam, muitas vezes não possibilitando os nexos entre os saberes sistematizados e a vida cotidiana. Essa articulação deve ganhar um

\footnotetext{
${ }^{3}$ Este termo vem de Santos (2016) e significa a articulação da democracia política com outros tipos de democracia e outros campos de democratização. Ele também a designa por democracia radical, de alta intensidade ou revolucionária.
} 
novo sentido pessoal, social e político para os cidadãos que se educam onde o currículo é um eixo transversal à vida.

Como não há neutralidade possível nos processos educativos, tais práticas têm significados político-sociais concretos que favorecem a produção de determinados tipos de conhecimentos e a não produção ou invisibilização de outros tipos de conhecimentos.

A universidade é um local estratégico para fazer a articulação dos saberes e dos espaços potencialmente significativos para os processos de formação e transformação social. Não se trata de um simples acúmulo de funções sobre a universidade e sim da possibilidade de ressignificação dos espaços-tempos de produção de saber e poder.

Temos em vista que, com a existência de diferentes modos de conhecer o mundo, os conteúdos educativos devem ser entendidos "não como um fim em si, mas como um meio de ampliação dos modos de compreensão do mundo, potencializando a intervenção sobre ele e capacitando a ação política e social emancipatória” (OLIVEIRA, 2008, p. 103-104).

O que se pretende é a aproximação com o que Freire (2014, p. 84) chama de transitividade crítica, a qual "com uma educação dialogal e ativa, voltada para a responsabilidade social e política, se caracteriza pela profundidade na interpretação dos problemas”. Em outras palavras, uma educação para a responsabilidade sócio-política, que objetiva a consideração dos diferentes conhecimentos que permeiam a realidade, que traz a ampliação e diversificação do que temos como fontes legítimas de saberes e que tenha a perspectiva da transformação social.

Nestes termos, a educação integral no ensino superior se liga com outros espaços sociais de construção de saberes não só pelo ensino, como também pela pesquisa e pela extensão, atividades que devem ser indissociáveis.

\section{CRÍTICA À EDUCAÇÃO PARA O MERCADO}

Acreditamos que não é qualquer educação que inevitavelmente seja uma prática de autonomia e liberdade dos sujeitos envolvidos. Por isso, há a necessidade de pensarmos uma educação que forneça as possibilidades de transformação social almejando a emancipação e que seja fundada na ética humana, no respeito à dignidade, na necessidade de formação integral e no desenvolvimento da própria autonomia dos(as) educandos(as).

Ou seja, a educação é importante enquanto possibilitadora da construção de alternativas e de perspectivas de transformação. Contudo, entendemos que ela só cumpre essas funções 
quando deixa de ser pensada como um fim em si mesma e é vista dentro das relações estruturais construídas historicamente e que a condicionam.

Neste sentido, um dos caminhos para a ressignificação da própria universidade, da educação, do conhecimento e da sociedade é o de assumir um papel que não seja a simples subserviência ao mercado capitalista. Ampliando a lógica única de uma formação técnica e profissional para dar mais ênfase em uma educação para a vida, para a cidadania e para a libertação. O que possibilita sair de uma ideia de universidade para uma universidade de ideias (como será trabalhado mais adiante no subitem 4).

Nossa compreensão é a de que não é possível o desenvolvimento de uma educação integral e emancipatória se, na verdade, o que se planeja são processos formativos que têm como único horizonte a integração ao mercado mundial capitalista. A incompatibilidade entre a educação integral e o capitalismo se mostra na impossibilidade de desenvolvermos um ser humano integral quando a educação é pensada em uma dimensão limitada de atender aos imperativos do capital e pouco ou nada se preocupa com o desenvolvimento das capacidades humanas em sentidos não mercadológicos.

É interessante notar que existem teorias sobre o fim da História e sobre a impossibilidade de ir além do Sistema Sociometabólico do Capital. O que faria inferir que, não havendo outras saídas, a única formação viável seja aquela apta a suprir as necessidades do sistema.

Conforme nos explica Mészáros (2007, p. 25), sobre a ideia de falta de possibilidades: "sua máxima impiedosa segundo a qual não há alternativa é somente uma variante propagandística da negação geral da história correspondente à natureza recôndita do capital no estágio atual do nosso desenvolvimento histórico". Não é à toa que as "personificações do capital” quando se deparam com os limites estruturais deste, logo abandonam suas teorias que prometiam um sistema mais humanizado e concentram suas energias propagandísticas em afirmar que não há solução.

Tendo a história como fio condutor da análise, entendemos o sistema sociometabólico de produção do Capital como não eterno e não absoluto, pois tem uma história, um começo, um desenvolvimento e provavelmente um fim.

Como não natural e não absoluto, uma questão crucial a ser debatida é sobre os imperativos de acumulação e de autoexpansão do Capital que se sobrepõem a ideia de suprir as necessidades e carências ${ }^{4}$ da humanidade. Temos uma produção de alimentos suficiente para

\footnotetext{
${ }^{4}$ Segundo Wolkmer (2009, p. 115): "A dinâmica das necessidades e das carências que permeia o indivíduo e a coletividade refere-se, tanto a um processo de subjetividade, modos de vida, desejos e valores, quanto à constante 'ausência' ou 'vazio' de algo almejado e nem sempre realizável. Por serem inesgotáveis e ilimitadas no tempo e no espaço, as necessidades humanas estão em permanente redefinição e recriação”.
} 
alimentar a população mundial e, mesmo assim, ainda persista a morte, fome ou subnutrição de milhares de pessoas por não terem o que comer. ${ }^{5}$ Ao mesmo tempo que há um enorme crescimento na produção de riquezas no mundo, de outra parte, há o aumento da pobreza, da concentração de rendas e das crises. Nas palavras de Mészáros:

O problema sério e em princípio insuperável para o sistema do capital é que ele sobrepõe às inevitáveis mediações de primeira ordem entre a humanidade e a natureza um conjunto de mediações alienantes de segunda ordem, criando, por meio disso, um círculo vicioso "eternizado" - e conceitualizado dessa maneira mesmo pelos maiores pensadores da burguesia - do qual não pode haver escapatória uma vez que se compartilhe da perspectiva do capital. (MÉSZÁROS, 2007, p. 41).

De acordo com Mészáros (2007), temos uma produção pela produção onde a interação sustentável entre os seres humanos e a natureza foram subvertidos sob os imperativos fetichistas do controle sociometabólico do capital. Não podemos lutar pelos objetivos mais imediatos como alimentação, moradia, saúde e educação básica para a maioria esmagadora da sociedade sem desafiar radicalmente a ordem estabelecida pelo capital.

Neste sentido, a educação integral no ensino superior é importante para desnaturalizar as relações absolutizadas pelo modo de produção e pelas relações sociais capitalistas. Contribuindo com a construção, descoberta ou afirmação de práticas sociais que sejam capazes de elucidar criticamente o sentido de tais relações.

É a partir do repensar, da análise crítica e da democratização dos espaços estruturais da sociedade que podemos produzir sujeitos autônomos, capazes de novas subjetividades e possibilitados de buscar a emancipação social.

De outro ponto, as possibilidades de ir além do capital e da construção de uma sociedade mais justa estão interligadas à necessidade de se pensar a democratização dos saberes. Em contraposição a sociedade do pensamento único que advoga única legitimidade ao pensamento científico ocidental que se tornou hegemônico sob a égide do capital.

Principalmente, na universidade, o saber da ciência se opõe cabalmente ao saber do senso comum ou outros saberes tradicionais e populares. Porém, a luta por emancipação deve vir

\footnotetext{
${ }^{5} \mathrm{O}$ grande problema da fome no mundo não está na produção, mas na distribuição. Segundo Navarro (2011), com dados de 2011: "Mais de 60 milhões de pessoas passam fome no mundo. Sessenta por cento são mulheres. Cada dia morrem por falta de alimentação suficiente, segundo dados da Organização das Nações Unidas, 24 mil pessoas. $\mathrm{Na}$ América Latina a falta de comida afeta 52,4 milhões de pessoas.

As mortes não têm a sua origem na escassez de comida, mas na pobreza e na desigualdade.

De acordo com o Fundo para a Agricultura e Alimentação (FAO), cada ano são produzidos alimentos suficientes para dar de comer a 12 bilhões de pessoas, isto é, o dobro dos habitantes do planeta. No entanto, milhões de seres humanos não podem adquiri-los porque não têm recursos para isso".
} 
acompanhada do entendimento de que as formas de saber hegemônicas privilegiam os que as detém e como não estão equitativamente distribuídas, geram uma desigualdade epistemológica e social.

Afinal, de nada adianta termos um saber científico muito bem elaborado e discutido dentro da academia se esses conhecimentos não são de acesso da maioria da população e não dialogam com os saberes construídos fora daquela. Portanto, há a necessidade de pensarmos a ecologia de saberes.

\section{ECOLOGIA DE SABERES: NO CAMINHO DO INTERCONHECIMENTO}

Se, contemporaneamente, há uma marcante legitimidade da ciência que a metamorfoseia em um conhecimento absoluto e induvidoso, de outro lado é importante e necessário advertir para os riscos de apensarmos como panaceia de todos os males ou ainda de a considerarmos como um fazer neutro, já que isso nos leva a uma atitude acrítica diante do fazer científico.

É de fácil compreensão a importância que a ciência tem hoje. Sendo, sem dúvida, difícil se contrapor às grandiosas possibilidades que ela colocou à disposição dos seres humanos. Por outro lado, a ciência também foi capaz de produzir a bomba atômica, os armamentos de destruição em massa de diversos tipos, a enorme destruição da natureza, as drogas sintéticas, os alimentos transgênicos e a gordura trans.

Ou seja, não deixam de existir os seus malefícios, pois que "a ciência moderna não foi, nos dois últimos séculos, nem um mal incondicional nem um bem incondicional" (SANTOS; MENEZES, 2009, p. 11). ${ }^{6}$ O problema surge quando a ciência é colocada enquanto caminho único, automático e sem volta. Vista, de antemão, como um saber superior a qualquer outro.

A hegemonia do fazer científico tem feito com que ela se autodetermine enquanto única lógica de conhecimento válida, acreditando ser universal e a única correta. Ocultando que tal pretensão de universalidade e validade é descontextualizada:

\footnotetext{
${ }^{6}$ Segundo Santos e Meneses (2009, p. 11), a ciência é, ela própria, "diversa internamente, o que lhe permite intervenções contraditórias na sociedade. E a verdade é que foi (e continua a ser) muitas vezes apropriada por grupos sociais subalternos e oprimidos para legitimar as suas causas e fortalecer as suas lutas. O importante numa avaliação histórica do papel da ciência é ter presente que os juízos epistemológicos sobre a ciência não podem ser feitos sem tomar em conta a institucionalidade que se constituiu com base nela. A epistemologia que conferiu à ciência a exclusividade do conhecimento válido traduziu-se num vasto aparato institucional - universidades, centros de investigação, sistema de peritos, pareceres técnicos - e foi ele que tornou mais difícil ou mesmo impossível o diálogo entre a ciência e os outros saberes".
} 
Toda a experiência social produz e reproduz conhecimento e, ao fazê-lo, pressupõe uma ou várias epistemologias. Epistemologia é toda a noção ou ideia, reflectida ou não, sobre as condições do que conta como conhecimento válido. É por via do conhecimento válido que uma dada experiência social se torna intencional e inteligível. Não há, pois, conhecimento sem práticas e actores sociais. E como umas e outros não existem senão no interior de relações sociais, diferentes tipos de relações sociais podem dar origem a diferentes epistemologias. As diferenças podem ser mínimas e, mesmo se grandes, podem não ser objecto de discussão, mas, em qualquer caso, estão muitas vezes na origem das tensões ou contradições presentes nas experiências sociais sobretudo quando, como é normalmente o caso, estas são constituídas por diferentes tipos de relações sociais. No seu sentido mais amplo, as relações sociais são sempre culturais (intra-culturais ou inter-culturais) e políticas (representam distribuições desiguais de poder). Assim sendo, qualquer conhecimento válido é sempre contextual, tanto em termos de diferença cultural como em termos de diferença política (SANTOS; MENEZES, 2009, p. 11).

A hegemonia e capacidade de auto validação colocam os malefícios dos empreendimentos científicos como horizontes aceitáveis, um mal menor, diante dos benefícios prometidos. Mas isso acaba por tornar o fazer científico uma crença de fé (não científica).

O que estamos a criticar não é apenas o potencial da ciência em si mesmo, mas sua capacidade de autocrítica e de diálogo com outros tipos de conhecimentos. Afinal, a própria ciência tem um contexto, não estando isolada do mundo como algo exterior à vivência humana, "Por isso, a exterioridade do conhecimento relativamente às condições que analisa é apenas provisória, estando momentaneamente suspensa entre uma interioridade passada ou préreflexiva, e uma interioridade futura ou pós-reflexiva" (SANTOS, 2011b, p. 55).

Os marcos de uma teoria crítica que rompam com o senso comum instituído, mas que retorne a ele como "uma ciência prudente para uma vida decente", não podem estar apenas e tão somente dentro da ciência moderna. Como alerta Santos (2010, 2011b), a razão moderna que tem presidido a racionalidade do mundo capitalista é uma razão indolente, metonímica e proléptica.

É uma racionalidade preguiçosa, que se pensa como única e deixa de pensar o futuro por acreditar em uma lógica do tempo linear onde o povir é simplesmente o progresso infinito do presente. Isso acarreta o desperdício da experiência, já que ela não reconhece aquilo que não a convém e invisibiliza uma multiplicidade de experiências disponíveis.

A universidade, ao dar privilégio ao conhecimento científico como o único verdadeiro, colaborou para injustiças cognitivas através da monocultura do saber: onde tudo aquilo que está fora dos critérios de verdade da ciência moderna é desqualificado, desprezado e invisibilizado de modo irreversível (SANTOS, 2010). A modernidade, fortemente pautada pelo colonialismo e pelo Sistema do Capital, com sua lógica produtivista, tem feito verdadeiros epistemicídios, destruindo outros tipos de conhecimento que não se enquadram no seu modo de ver o mundo. 
Os epistemicídios decorrem do modo de intervenção da ciência moderna ao desacreditar e até suprimir "as práticas sociais de conhecimento que contrariassem os interesses que ela servia” (SANTOS; MENESES, 2009, p. 10). Isso significou a supressão dos conhecimentos locais em favor de um conhecimento dito "universal" a partir da tentativa de homogeneizar o mundo com o desaparecimento das diferenças culturais. Tudo isso levou a um desperdício de muita experiência social e da reduçãoda diversidade epistemológica, cultural e política do mundo (SANTOS; MENESES, 2009).

Diante da diversidade do mundo é indiscutível a necessidade de pensarmos a democratização dos conhecimentos. Não só democratização do conhecimento hegemônico, mas a possibilidade de valorização e legitimidade de outros tipos de conhecimento muitas vezes invisibilizados.

Em outras palavras, a ideia de educação integral, aqui proposta, vai além da possibilidade de adquirir e universalizar os conhecimentos científicos "necessários", pois é fundamental que haja o reconhecimento, valorização e legitimação de outras formas de conhecimento. Tal ideia tem como base o "reconhecimento da pluralidade de saberes heterogêneos, da autonomia de cada um deles e da articulação sistêmica, dinâmica e horizontal entre eles” (SANTOS, 2010, p. 157).

$\mathrm{O}$ acesso à forma de saber prevalente gera poder, contudo, as alternativas para combater as injustiças cognitivas não se dão apenas por distribuí-lo melhor e assim o seu poder. Devemos buscar uma horizontalização na relação entre as diferentes formas de conhecer que permeiam o mundo.

Para tal intento leva-se a cabo a proposta de Santos (2010, p. 154) no que ele denomina de ecologia de saberes. Esta é "um conjunto de epistemologias que partem da possibilidade da diversidade e da globalização contra-hegemônica ${ }^{7}$ e pretendem contribuir para as credibilizar e fortalecer". Mas não só um conjunto de epistemologias, como também:

[...] conjuntos de práticas que promovem uma nova convivência activa de saberes no pressuposto que todos eles, incluindo o saber científico, se podem enriquecer nesse diálogo. Implica uma vasta gama de acções de valorização, tanto do conhecimento científico, como de outros conhecimentos práticos, considerados úteis, cuja partilha por pesquisadores, estudantes e grupos de cidadãos serve de base à criação de comunidades epistémicas mais amplas que convertem a universidade num espaço público de interconhecimento onde os cidadãos e os grupos sociais podem intervir sem ser exclusivamente na posição de aprendizes (SANTOS, 2011a, p. 77).

\footnotetext{
${ }^{7}$ Conforme Santos (2010, p. 400): "Designo por globalização contra-hegemônica o conjunto vasto de redes, iniciativas, organizações e movimentos que lutam contra as consequências econômicas, sociais, políticas e culturais da globalização hegemônica e que se opõem às concepções de desenvolvimento mundial a esta subjacentes, ao mesmo tempo que propõem concepções alternativas".
} 
A Ciência Moderna não é a única explicação possível da realidade. Há uma enorme diversidade epistemológica, ontológica e cultural no mundo e a razão para que aquela seja hegemônica não é uma razão puramente científica, mas fatores construídos historicamente que se mantém por juízos de valores naturalizados com o tempo. O que não significa desconsiderar a importância da ciência para a humanidade, mas reconsiderar a importância de outros conhecimentos que, muitas vezes, se traduzem em múltiplas concepções de ser e estar no mundo. ${ }^{8}$

Chauí (2013, p. 36) afirma que: “[...] o que a ecologia de saberes combate são as hierarquias e poderes universais e abstratos, naturalizados pela história e por epistemologias reducionistas". Ou seja, "Busca-se, neste sentido, estabelecer conexões solidárias e transformadoras entre a ciência e as outras formas de conhecimento com a finalidade de produzir interconhecimento" (SILVA; SILVA, 2014, p. 169). ${ }^{9}$

Todos os conhecimentos são contextuais e parciais, não há conhecimentos puros ou totais, daí a importância da crítica à ciência como saber universal. A ecologia de saberes serve para credibilizar e fortalecer outros tipos de conhecimentos, reconhecendo a impossibilidade de neutralidade das epistemologias e que a reflexão sobre os conhecimentos deve incidir sobre as práticas de conhecimento e seus impactos.

Cremos ser necessário, então, a transformação de uma ideia de universidade em uma universidade de ideias, onde a universidade estará permeada por muitas racionalidades ${ }^{10}$, por múltiplos saberes e pelo enredamento entre as diferentes dimensões do conhecer. Onde não terá lugar uma única ideia de universidade, mas a construção coletiva de universidades que partem do diálogo entre saberes e da democratização de espaços estruturais.

\footnotetext{
${ }^{8}$ Como adverte Miglievich-Ribeiro (2014), a crítica à modernidade e à ciência moderna não significa um desprezo por seus significados. Não se desprezam valores como "liberdade, igualdade, democracia ou os direitos humanos" (MIGLIEVICH-RIBEIRO, 2014, p. 68). O que se pretende é a contextualização das categorias explicativas que até então eram tidas como absolutas por serem naturalizadas.

9 “A utopia do interconhecimento é aprender outros conhecimentos sem esquecer os próprios” (CHAUÍ, 2013, p. 34).

10 "Uma racionalidade feita de racionalidades. Para que esta configuração de conhecimentos ocorra é necessário inverter a ruptura epistemológica. Na ciência moderna a ruptura epistemológica simboliza o salto qualitativo do conhecimento do senso comum para o conhecimento científico; na ciência pós-moderna o salto mais importante é o que é dado do conhecimento científico para o conhecimento do senso comum. O conhecimento científico pósmoderno só se realiza enquanto tal na medida em que se converte em senso comum" (SANTOS, 1988, p. 70).
} 


\section{DA IDEIA DE UNIVERSIDADE À UNIVERSIDADE DE IDEIAS: DA CRISE À CONSTRUÇÃO DE UMA UNIVERSIDADE POPULAR}

Um dos aspectos da crise pela qual passa a universidade está no fato de ela se deparar "premida entre uma sociedade de direitos e uma sociedade de mercado, entre a proposta de pesquisa, o ensino e a extensão voltados para a garantia de processos de humanização e outra, cujo escopo maior é o de atender ao mercado" (CORREIA, 2016, p. 4).

Mas outros aspectos importantes estão inter-relacionados com a própria crise da modernidade e da ciência. Para Santos (2011a), são três as crises que afetam a universidade: crise de hegemonia, crise de legitimidade e crise institucional. A primeira (de hegemonia) foi resultado da incapacidade da universidade em desempenhar de forma satisfatória funções contraditórias que lhe foram atribuídas. Como não conseguiu cumprir de maneira cabal essas funções, tanto o Estado quanto os agentes econômicos se viram obrigados a procurar meios alternativos fora da universidade, rompendo com sua hegemonia sobre o ensino superior e produção de pesquisa.

Quanto à crise de legitimidade, podemos afirmar que foi provocada pela maior reinvindicação de setores da classe média e popular por acesso à educação superior, no sentido de que esta não ficasse restrita à formação das elites. A universidade deixou de ser uma instituição consensual por não resolver a contradição entre as expectativas de sua democratização com possibilidade de acesso das classes populares e "[...] a hierarquização dos saberes especializados através das restrições do acesso e da credenciação das competências" (SANTOS, 2011a, p. 9-10).

Já a crise institucional foi resultado principalmente de sua crise de autonomia. A base dessa crise é outra grande contradição entre a exigência de autonomia das universidades para a definição dos seus objetivos e valores em contraposição a uma enorme pressão pela sua submissão a "critérios de eficácia e de produtividade de natureza empresarial ou de responsabilidade social" (SANTOS, 2011a, p. 9-10). Essa crise se expressa sob três fatores: financiamento, avaliação externa e produtivismo.

Com a crise do Estado providência e com a hegemonia das políticas neoliberais o financiamento da universidade é reduzido e ela é obrigada a buscar outros meios de captar recursos, de qualquer modo acaba por sofrer com cortes orçamentários significativos. Outro ponto determinante é que os agentes econômicos e o próprio Estado acabam por formatar uma avaliação externa à universidade colocando a produtividade como critério principal de 
avaliação. Por último, o produtivismo assume parte da crise, pois ela passa a ser obrigada a entrar na lógica da produção industrial já que tem que estar vinculada aos novos critérios em busca de financiamento.

Na contramão do pensamento dominante, acreditamos que a universidade deve encampar as necessidades das classes populares. Deve ser pensada a partir das carências sociais e, ao invés de ser tratada como um modelo único de universidade, deve ser pensada como lócus de pluralidade de ideias.

Diante da diversidade epistemológica e social é preciso que pensemos em uma instituição que seja capaz de produzir relações horizontalizadas entre os conhecimentos. De modo que, a partir dela, possamos construir relações de autoridade partilhada e escapar das hierarquias abstratamente edificadas.

Aliás, universidade moderna está intimamente ligada ao Estado moderno e se tornou uma instituição hegemônica, de produção de conhecimento, junto com a consolidação da sociedade industrial (GROPPO, 2011). Nesse sentido, é preciso construirmos uma nova instituição. Uma que esteja mais ligada à(s) comunidade(s) e ao povo, que seja a base de consolidação de uma nova sociedade e que seja capaz de produzir um diálogo construtivo entre as diversas racionalidades.

\section{CONCLUSÃO}

Atualmente não é incomum, no nosso meio, que as universidades tenham como principais objetivos a capacitação para o capital e seus mercados. Isso é fruto da absorção das demandas do capitalismo mundial. Contudo, essa vinculação tem estreitado os horizontes do ensino, da pesquisa e da extensão universitários.

Para caminhar em sentido contrário e desempenhar uma função de emancipação é indispensável que as Instituições de Ensino Superior (IES) não mais estejam a serviço do capital, que seu fundamento não seja servir às necessidades do mercado enquanto necessidades de segunda ordem.

Mais do que formar mão de obra qualificada ou, ainda, repassar conhecimentos que trazem uma perspectiva de gerar poder social e melhoria de vida individual de poucos(as) acadêmicos(as) na acirrada competição por empregos, a nova universidade deve ter como pauta o reconhecimento da pluralidade de saberes e a necessidade de sua democratização em busca da emancipação social, distribuição de poderes, dissolução de hierarquias abstratas e efetivação de autoridades partilhadas. 
Não se trata de abrir mão de métodos, critérios ou do conhecimento sistematizado, mas de garantir o diálogo entre as diferentes formas de conhecer para o fortalecimento de alternativas plurais. Colocar a ciência como absoluta é uma escolha de fé, já que mesmo o conhecimento produzido por esta é apenas aproximado ao objeto e nunca um conhecimento total ou objetivo.

Para construirmos uma educação integral emancipatória e uma universidade de ideias é necessária a luta pela democratização dos espaços estruturais da sociedade e é importante a construção de outro modelo de produção e distribuição das riquezas. As lutas estão imbricadas, e devem ser alimentadas por interconhecimento, pois não é possível construir uma educação realmente integral e emancipatória, que busque o rompimento da contradição (insolúvel dentro do capitalismo) entre capital e trabalho, sem a aceitação da pluralidade do mundo.

\section{Referências}

ARANHA, G. A. Introdução crítica ao direito: em busca do equilíbrio entre regulação e emancipação. 1. ed. São Paulo: Paulus, 2011.

CHAUÍ, M. S. Saudação a Boaventura de Sousa Santos. In: SANTOS, B. de S. Direitos humanos, democracia e desenvolvimento. São Paulo: Cortez, 2013.

COELHO, L. M. C. C. História(s) da educação integral. Em Aberto, Brasília, v. 22, n. 80, p. 83-96, 2009.

CORREIA, W. Reuni: vamos continuar calados? Espaço Acadêmico, Maringá, n. 82, p. 1-5, mar. 2008. Disponível em: <https://goo.gl/Lp8wHC>. Acesso em: 20 jul. 2016.

FOSTER, J. B. Prefácio. In: MÉSZÁROS, I. O desafio e o fardo do tempo histórico: o socialismo no século XXI. Tradução Ana Cotrim, Vera Cotrim. São Paulo: Boitempo, 2007.

FREIRE, P. Educação como prática da liberdade. 36. ed. São Paulo: Paz e Terra, 2014.

GUARÁ, I. M. F. R. É imprescindível educar integralmente. Cadernos Cenpec, São Paulo, n. 2, p. 15-24, 2006.

GROPPO, L. A. Da universidade autônoma ao ensino superior operacional: considerações sobre a crise da universidade e a crise do estado nacional. Avaliação, Campinas; Sorocaba, v. 16, n. 1, p. 37-55, 2011.

MÉSZÁROS, I. O desafio e o fardo do tempo histórico: o socialismo no século XXI. Tradução Ana Cotrim, Vera Cotrim. São Paulo: Boitempo, 2007.

MIGLIEVICH-RIBEIRO, A. M. Por uma razão decolonial: desafios ético-políticoepistemológicos à cosmovisão moderna. Civitas, Porto Alegre, v. 14, n. 1, p. 66-80, 2014. 
MOLL, J. Conceitos e pressupostos: o que queremos quando falamos de educação integral? Salto para o Futuro, Brasília, ano 18, boletim 13, p. 11-16, 2008.

(Org.). Caminhos para elaborar uma proposta de educação integral em jornada ampliada: como ampliar tempos, espaços e oportunidades educativas para crianças, adolescentes e jovens aprenderem. Brasília: SEB/MEC, 2011.

NAVARRO, L. H. A política da fome do capitalismo. Blog do Miro, 7 mar. 2011. Disponível em: $<$ https://goo.gl/MMfkSv>. Acesso em: 22 jul. 2016.

OLIVEIRA, I. B. Boaventura \& a educação. 2. ed. Belo Horizonte: Autêntica, 2008.

SANTOS, B. S. Um discurso sobre as ciências na transição para uma ciência pós-moderna. Estudos Avançados, São Paulo, v. 2, n. 2, p. 46-71, 1988. Disponível em: <https://goo. gl/9Z53Mv>. Acesso em: 20 dez. 2017.

. A gramática do tempo: para uma nova cultura política. 3. ed. São Paulo: Cortez, 2010 .

. A universidade no século XXI: para uma reforma democrática e emancipatória da universidade. 3. ed. São Paulo: Cortez, 2011a.

. Para um novo senso comum: a ciência, o direito e a política na transição paradigmática. 8. ed. São Paulo: Cortez, 2011 b.

. A difícil democracia: reinventar as esquerdas. 1. ed. São Paulo: Boitempo, 2016.

SANTOS, B. S.; MENESES, P. M. G. Epistemologias do Sul. Coimbra: Almedina, 2009.

SILVA, F. G. P.; SILVA, J. F. A crítica decolonial das epistemologias do Sul e o contexto de constituição das coleções didáticas do PNLD-Campo/2013. Realis - Revista de Estudos AntiUtilitaristas e PosColoniais, Recife, v. 4, n. 2, p. 149-174, 2014.

WOLKMER, A. C. Introdução ao pensamento jurídico crítico. 7. ed. São Paulo: Saraiva, 2009.

Recebido em: 03/11/2016

Revisado em: 29/12/2017

Aprovado para publicação em: 30/12/2017

Publicado em: 30/12/2017 